\title{
Correspondence
}

\section{Paracetamol and risk factors in Newcastle}

Restrictions on easy access to paracetamol have reduced death from paracetamol overdose in the UK. However, figures from Newcastle show that hanging and jumping deaths have become more common. ${ }^{1}$ Since paracetamol overdoses are usually not instantly fatal, second thoughts are possible. This is not the case with hanging and jumping. Is this an unintended consequence of paracetamol restrictions? Treating paracetamol overdose is expensive for the National Health Service but surely it is a worthwhile expenditure. Does this make a case for easing restrictions on access to paracetamol?

Alasdair J. Macdonald, retired consultant psychiatrist, UK; email: macdonald@solutionsdoc.co.uk

1 Linsley KR, Schapira MA, Schapira K, Lister C. Changes in risk factors for young male suicide in Newcastle upon Tyne, 1961-2009. BJPsych Bull 2016; 40: 136-141.

doi: $10.1192 / p b .40 .5 .285$

\section{Terrorism: it's not mental illness - it's politics}

Hurlow et $a^{1}$ appear to argue that psychiatrists have a major role in preventing terrorism. This might lead one to think that there has been a massive wave of attacks by people who are mentally ill. In fact, Britain is fortunate to have had only one terrorism-related murder since 2005!

By contrast, Northern Ireland saw almost 1000 terrorist killings by unionists/loyalists and 2000 by nationalists/ republicans - Dr Hurlow's home city of Birmingham had 21 people killed in the 1974 IRA bombings. The contribution of mental illness to the 3000 killings was, in essence, totally negligible. Indeed Lyons et $a l^{2}$ noted that terrorists were mentally healthier than 'ordinary' killers. This has face validity: it is doubtful that a person or persons with psychosis could plan and execute the sort of sophisticated attacks we have witnessed in Birmingham, Brighton, Enniskillen, Madrid and London. Did police contact psychiatric services in the wake of the Paris attacks in November 2015? Of course not! Terrorism is, by definition, politically motivated.

Politicians, the media and others all too often respond to terrorism by lazily and superficially claiming it to be 'psychotic', 'crazy', 'insane', 'psychopathic' or (most mindlessly of all) 'mindless'. Islamic State are disgustingly murderous, but Abu Bakr al-Baghdadi and his activists are not driven by mental illness. It is very worrisome if psychiatrists contribute to this unscientific discourse.

There will always be a tiny number of mentally disturbed people who respond to the current zeitgeist and act out violent fantasies. Psychiatrists must always take account of the risk to other people from such individuals and act appropriately. However, to extrapolate from this a new obligation to routinely monitor our patients and work in close contact with antiterrorism policing is both stigmatising to people with a mental illness, and damaging to our independence and professional reputation. Crucially, it is also useless in preventing serious terrorism. If colleagues are in any doubt about this, I would suggest that they speak to the real experts in terrorism: senior police officers in Northern Ireland.

Philip J. McGarry, consultant psychiatrist, Belfast Health and Social Care Trust, Belfast, UK; email: philip.mcgarry@me.com

1 Hurlow J, Wilson S, James DV. Protesting loudly about Prevent is popular but is it informed and sensible? BJPsych Bull 2016; 40: 162-3.

2 Lyons $\mathrm{H}$, Harbinson $\mathrm{H}$. A comparison of political and non-political murderers in Northern Ireland, 1974-1984. Med Sci Law 1986; 26: 193-7.

doi: $10.1192 / p b .40 .5 .285 a$

\section{Guidance on advance care planning}

Waterman et $a^{1}$ perform a useful service in drawing attention to the need for psychiatric in-patient units to develop expertise in terminal care. It is a shame that they have not acknowledged the guidance on advance care planning developed by the Royal College of Physicians ${ }^{2}$ in conjunction with the Alzheimer's Society, the Royal College of Psychiatrists, and other lay and professional groups.

The authors have also misunderstood the status of advanced decisions to refuse treatment made under the Mental Capacity Act 2005. To be valid, an advanced decision must specify a particular treatment which is not to be carried out or continued (section 4 of the Act). It is not possible to make an advance decision to die at home and not go into residential care (although it would not be possible to use the Deprivation of Liberty Safeguards to require a person to stay in hospital to receive treatment that had been refused in advance). It is not possible to require health care professionals to provide a specified treatment. ${ }^{3}$

It is best to regard advance care plans as statements of wishes and feelings about what is in the patient's best interests. The Mental Capacity Act places particular emphasis on relevant written statements made by the patient when he/ she had capacity (section 6a; see also the Mental Capacity Act Code of Practice, paragraphs 5.40-5.45). There are likely to be times when most psychiatric patients will lose capacity to make some decisions. Ascertaining how patients would like to be treated when they are unable to make decisions for themselves should be part of routine practice with all psychiatric patients.

\section{Declaration of interest}

J.W. has been appointed as a Court of Protection Special Visitor under section 61 of the Mental Capacity Act.

Jonathan Waite, consultant psychiatrist, Nottinghamshire Healthcare Foundation Trust, Nottingham, UK; email: Jonathan.Waite@nottshc.nhs.uk

1 Waterman LZ, Denton D, Minton O. End-of-life care in a psychiatric hospital. BJPsych Bull 2016; 40: 149-152.

2 Advance Care Planning: National Guidelines. Royal College of Physicians, 2009. Available at: https://www.rcplondon.ac.uk/guidelines-policy/ advance-care-planning.

3 R (Burke) v GMC [2005] EWCA Civ 1003.

doi: $10.1192 / p b .40 .5 .285 b$ 